\title{
Beyond Learning Management Systems: Designing for Interprofessional Knowledge Building in the Health Sciences
}

\section{Au-delà des systèmes de gestion de l'apprentissage: concevoir la coélaboration de connaissances interprofessionnelle en sciences de la santé}

Leila Lax, Marlene Scardamalia, Judy Watt-Watson, Judith Hunter, and Carl Bereiter

\begin{abstract}
Authors
Leila Lax, Assistant Professor, Department of Biology, University of Toronto Mississauga \& Institute of Medical Science, Faculty of Medicine, University of Toronto. Correspondence regarding this article can be sent to l.lax@utoronto.ca

Marlene Scardamalia, Presidents' Chair in Education and Knowledge Technologies and Director of the Institute for Knowledge Innovation and Technology, OISE, University of Toronto.

Judy Watt-Watson, Professor Emerita and Executive Director of the Centre for Advanced Studies in Professional Practice, Lawrence S. Bloomberg Faculty of Nursing, University of Toronto Judith Hunter, Assistant Professor, Department of Physical Therapy, Faculty of Medicine, University of Toronto.

Carl Bereiter, Professor Emeritus, Institute for Knowledge Innovation and Technology, OISE, University of Toronto.
\end{abstract}

\begin{abstract}
This paper examines theoretical, pedagogical, and technological differences between two technologies that have been used in undergraduate interprofessional health sciences at the University of Toronto. One, a learning management system, WebCT 2.0, supports online coursework. The other, a Knowledge Building environment, Knowledge Forum 2.0, supports the collaborative work of knowledge-creating communities. Seventy students from six health science programs (Dentistry, Medicine, Nursing, Occupational Therapy, Pharmacy and Physical Therapy) participated online in a 5-day initiative to advance understanding of core principles and professional roles in pain assessment and management. Knowledge Forum functioned well as a learning management system but to preserve comparability between the two technologies its full resources were not brought into play. In this paper we examine three distinctive affordances of Knowledge Forum that have implications for health sciences education: (1) supports for Knowledge Building discourse as distinct from standard threaded discourse; (2) integration of sociocognitive functions as distinct from an assortment of separate tools; and (3) resources for multidimensional social and cognitive assessment that go beyond common participation indicators and instructor-designed quizzes and analyses. We argue that these design characteristics have the potential to open educational pathways that traditional learning management systems leave closed.
\end{abstract}




\section{Résumé}

Cet article examine les différences théoriques, pédagogiques et technologiques entre deux technologies utilisées en sciences de la santé interprofessionnelles de premier cycle à I'Université de Toronto. Une, un système de gestion de l'apprentissage, WebCT 2.0, soutient le travail en ligne. L'autre, un environnement de coélaboration de connaissances, Knowledge Forum 2.0, permet le travail collaboratif entre les communautés de création de la connaissance. Soixante-dix étudiants de six programmes de sciences de la santé (médecine dentaire, médecine, soins infirmiers, thérapie occupationnelle, pharmacie et physiothérapie) ont participé en ligne à un cours de cinq jours pour améliorer leur compréhension des principes de base et des rôles professionnels dans l'évaluation et la gestion de la douleur. Knowledge Forum a bien fonctionné en tant que système de gestion de l'apprentissage. Cependant, afin de permettre la comparaison entre les deux technologies, toutes ses fonctionnalités n'ont pas été utilisées. Dans ce texte, nous examinons trois possibilités distinctes de Knowledge Forum qui ont des implications sur le développement de l'éducation en sciences de la santé : (1) soutenir le discours en coélaboration de connaissances de façon distincte des fils de discussion couramment employés; (2) intégrer des fonctions sociocognitives distinctes d'un ensemble d'outils séparés et (3) procurer des ressources pour l'évaluation sociale multidimensionnelle et cognitive qui vont au-delà des indicateurs communs de participation et des exercices et analyses créés par l'instructeur. Nous avançons que ces caractéristiques ont le potentiel de susciter des pistes éducatives que les systèmes de gestion de l’apprentissage traditionnels ne parviennent pas à ouvrir.

\section{Introduction}

Although a number of studies and reports have begun to identify educational innovations for Knowledge Building (see articles throughout this special issue; also Lee, Chan, van Aalst, 2006; Scardamalia, Bransford, Kozma, \& Quellmalz, in press; Zhang, Scardamalia, Lamon, Messina, \& Reeve, 2007), no known studies compare existing technologies from the standpoint of their favouring or impeding Knowledge Building. However, a study was conducted in an interprofessional health sciences curriculum at the University of Toronto that assigned some students to use of Knowledge Forum 2.0 while others used WebCT 2.0. The upshot of this study was that, on various measures of participation, learning, and satisfaction, Knowledge Forum's performance as a course delivery platform was equal to that of a technology designed specifically for that purpose; accordingly, it was used subsequently in more extended ways, within the pain curriculum and in the development of another course (Lax, Watt-Watson, Pennefather, Hunter, \& Scardamalia, 2003; Lax Singh, Scardamalia \& Librach, 2006).

The present paper carries on from this study to consider how Knowledge Forum's unique affordances could be used in the same course context to advance Knowledge Building objectives. After describing the nature of the course, we consider three Knowledge Forum affordances that could enrich the course's Knowledge Building potential: (1) supports for Knowledge Building discourse as distinct from standard threaded discourse; (2) integration of sociocognitive functions as distinct from an assortment of separate tools; and (3) resources for

Beyond Learning Management Systems: Designing for Interprofessional Knowledge Building in the Health Sciences 
multidimensional social and cognitive assessment that go beyond common participation indicators and instructor-designed quizzes and analyses.

\section{Conceptual Underpinnings: Learning Management Systems and Knowledge Building Environments}

In knowledge based organizations one technology (sometimes called "knowledgeware") is used in the creative work of the organization and an entirely separate technology is used for learning. Both economically and technologically, e-learning is treated as a separate world from the ongoing creative work of an organization. WebCT 2.0, one of the technologies used in the pain interprofessional health sciences initiative represents a learning management system. Widely used in both formal education and in corporate learning environments, it was developed to provide "an easy-to-use environment for creating WWW-based courses" (Goldberg, Salari, \& Swoboda, 1996). It allowed course authors to create a course and then add a wide variety of tools and features including discussion boards, student self-evaluation, timed quizzes, and electronic mail. New features have been continually added.

In contrast to learning management systems, Knowledge Forum, the other technology used in the present study, is as a Knowledge Building environment (Scardamalia, 2003). In line with the goal of bringing more creative work with ideas to education, a Knowledge Forum aims to bring the worlds of knowledge work and e-learning together into one coherent framework. As argued by Scardamalia, these two worlds need not be so separate, in that collaborative creation of new knowledge can be the mainstay of education as well as of innovation-producing organizations of all kinds. As indicated in this report, Knowledge Forum 2.0 can be used as a learning management system in much the same way as WebCT 2,0; but, as our analysis will show, Knowledge Building environments have the potential to go beyond learning management systems to support functions essential to sustaining knowledge creating enterprises. These include deeper inquiry, higher levels of agency in knowledge work, and more imaginative and venturesome means for student work to be integrated with out-of-school Knowledge Building enterprises.

\section{The University of Toronto Centre for the Study of Pain - Interfaculty Education Opportunity}

Until recently, most interprofessional educational opportunities for health science students occur after their licensure (Cooper, Carlisle, Gibbs, \& Watkins, 2001). Current research by Health Canada (D'Amour, \& Oandasan, 2004) and others (Barr, Koppel, Reeves, Hammick, \& Freeth, 2005; Hall \& Weaver, 2001; Horsburgh, Lamdin, \& Williamson, 2001; Zwarenstein, Reeves, Barr, Hammick, Koppel, et al., 2001) advocates early interprofessional integration during undergraduate health sciences education. In response to the need for innovation in its programs, in 2002 the Interfaculty Pain Curriculum Committee, supported by the University of Toronto Centre for the Study of Pain and the Council of Health Science and Social Work Deans, developed a 20-hour face-to-face curriculum for undergraduate students in six health science professional programs. The University of Toronto Centre for the Study of Pain - Interfaculty Pain Curriculum (UTCSP-IPC) consisted of large group didactic lectures and small group, face-to-face

Beyond Learning Management Systems: Designing for Interprofessional Knowledge Building in the Health Sciences 
case meetings; the goal was to advance current pain knowledge and engage participants in interprofessional communication. In its inaugural year, 540 students participated and the curriculum was called "Pain: A Multidimensional Issue," (for details see Watt-Watson et al., 2004). The 5-day initiative represented an important first step in advancing collaborative Knowledge Building for interprofessional education across a large university campus. The designs to support case-based reasoning that were successfully incorporated into two different technological environments included authentic clinical scenarios, clinician-expert feedback, attention to misconceptions, interdisciplinary teams functioning interactively and successfully to improve pain management. Students came together as a community and could experience how individuals from different disciplines think about pain treatment and can support each other. This is not an opportunity usually afforded to pre-licensure health professionals.

In addition to the face-to-face program indicated above an online component, called the University of Toronto Centre for the Study of Pain - Interfaculty Education Opportunity (UTCSPIFEO), was offered to explore e-learning and interdisciplinary Knowledge Building. The students, typically separated by disciplines, schedules, and buildings, were offered an opportunity to participate in what was termed an interprofessional collaborative Knowledge Building study. The following are excerpts from the invitations and consent forms emailed, in February/March 2002, to all 540 students:

You will be participating in a University of Toronto Centre for the Study of Pain Interfaculty Education Opportunity (UTCSP-IFEO), called Pain: A Multidimensional Issue. In addition to the morning face-to-face learning sessions we would like to invite you to participate in a unique online learning study where you will have the opportunity to examine the multidimensional nature of pain in more depth. Overview: Web Knowledge Forum and WebCT are the two internet-based learning environments that have been chosen for use. No prior knowledge or experience in online learning is required. ...

Participation in this study will require approx. 1 hour per day of work online for the 5 days of Pain Week. An unfolding clinical case scenario will be presented ... the purpose is to collaboratively analyze and discuss issues of pain assessment and management and to develop a deeper understanding of health professional team roles. At the conclusion of Pain Week you will be asked to fill out an e-learning survey...

In response to this invitation 70 students signed up for the online initiative. The students came from third-year Dentistry and Pharmacy, and second-year Medicine, Nursing, Occupational Therapy, and Physical Therapy. The 70 volunteers were randomly stratified by discipline into teams, and further randomly assigned to work in one of two technology platforms selected for the e-learning work. They were given access to their respective technologies through the pain curriculum Web site [http://icarus.med.utoronto.ca/pain/] designed by the principal investigator (Figure 1).

Beyond Learning Management Systems: Designing for Interprofessional Knowledge Building in the Health Sciences 


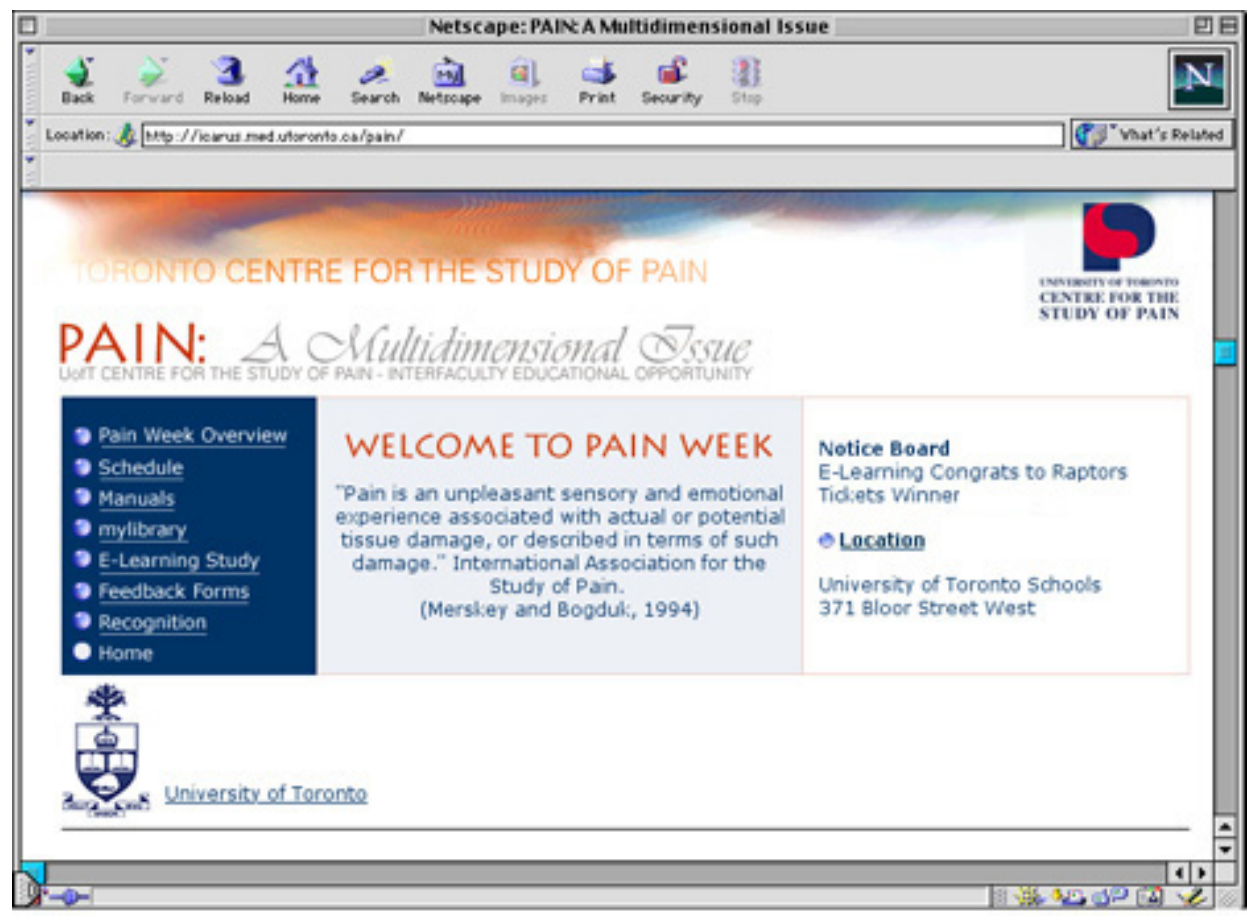

Figure 1: The interprofessional pain curriculum Web site provided access to WebCT 2.0 and Knowledge Forum 2.0.

Regardless of what technology they were to use, all 70 students were introduced to the concept of Knowledge Building, and told it involves "working together to advance knowledge, understanding, and examination of personal biases." They were asked to attend one of three, 1hour, hands-on orientation sessions. At the orientation session, participants were provided with an overview of the technology they would use. They received a sheet with further information regarding access and names of team members. Three UTCSP-IPC committee members and another colleague, including academics and expert-clinicians from medicine, nursing and physical therapy, facilitated online discourse in both environments.

Student participants discussed pain issues in their respective online asynchronous environments, focusing on a phantom pain case throughout the full 5-day initiative. This case was different from the cancer pain case used in the small group, problem-based learning sessions involving face-to-face discussions.

Participants worked online in their interprofessional teams every day except for Day 3. On that day, a jigsaw strategy was used (Cooney \& Bielaczyc, 2003). Participants were asked to first work in uniprofessional groups, according to their educational discipline, and to develop a patientmanagement plan. The next day, participants were asked to work in their interprofessional groups, share their discipline-based management plans, and collaboratively construct an interprofessional care plan, while intentionally trying to advance collective knowledge and ideas.

Beyond Learning Management Systems: Designing for Interprofessional Knowledge Building in the Health Sciences 
Students and facilitators were asked to log in daily, at their convenience, throughout the week. Participants' note contributions were automatically saved.

\section{Affordances for Knowledge Building}

A principal concern of the committee in charge of this program was to determine whether the Knowledge Building environment, Knowledge Forum could serve as adequately for course delivery as the learning management system, WebCT, which was designed for that purpose and for which the university already had a license. As reported in Lax, Watt-Watson, Pennefather, Hunter, and Scardamalia, (2002), the two technologies performed well according to measures of participation, learning, and satisfaction. This finding of equivalence for course delivery was important, because it cleared the way for Knowledge Forum use in the subsequent year with greater scope for its implementation as a Knowledge Building environment and its use in the development of other programs (Lax, et al., 2003; Lax, et al., 2006). In this study, the faculty were committed to Knowledge Building, all participants in the online options received an introduction to Knowledge Building ideas, and facilitators encouraged discourse in keeping with Knowledge Building principles. The pain curriculum provided an unusually promising context within which to pursue the central objective of Knowledge Building-the collaborative construction of public knowledge of value to the community. However, the need to preserve comparability between the two technologies meant that technological support for Knowledge Building was limited to what could be provided by both technologies, with few exceptions. And the few distinctive features of Knowledge Forum incorporated into the 5-day course were not used long enough to test their potential for reconstructing the class as a Knowledge Building community.

The circumstances of this early effort thus made it impossible to judge what might have been achieved had all of Knowledge Forum's affordances for Knowledge Building been applied. Accordingly, we turn to a consideration of three affordances of Knowledge Forum that hold promise for realizing the Knowledge Building potential of interprofessional education: (1) supports for Knowledge Building discourse as distinct from standard threaded discourse; (2) integration of sociocognitive functions as distinct from an assortment of separate tools; and (3) resources for multidimensional social and cognitive assessment that go beyond common participation indicators and instructor-designed quizzes and analyses.

For each of the three design features we incorporate a discussion of next-generation designs to convey the match between Knowledge Building principles and special affordances of the technology, principles are indicated in italics throughout the discussion. We do not provide a general description of Knowledge Forum because it is discussed in articles throughout this special issue (see especially Gan, Scardamalia, Hong, \& Zhang; Hong, Scardamalia, \& Zhang; Moss \& Beatty; Sun, Zhang, \& Scardamalia, present issue; also see Scardamalia \& Bereiter, 2003).

Beyond Learning Management Systems: Designing for Interprofessional Knowledge Building in the Health Sciences 


\section{Supports for Knowledge Building discourse as distinct from standard threaded discourse}

As elaborated by Scardamalia and Bereiter (2006), a distinctive characteristic of Knowledge Forum is the system of supports it provides for Knowledge Building discourse. In contrast, learning management systems like Blackboard, Moodle, and Desire2Learn, along with innumerable discussion boards found throughout the Worldwide Web, provide no discourse support beyond "threading." A threaded discussion is a one-to-many form of e-mail in which the sender "posts" a message to a discussion site and all posted messages appear in chronological order, except for responses indented under the original message. Responses to those responses are further indented, and so on, forming a "thread." The conceptual model, from the students' point-of-view, is "post-and-respond." Research (Davie, Abeygunawardena, Davidson, \& Nolan, 1998; Hewitt, 1997) has shown that the hierarchical organization of discussion threads and the pattern of individual, serial note response (e.g., post, reply, reply, reply; post, reply, reply, reply) discourage convergence of ideas and lead to gradual diffusion of discourse, conversational drift, and fragmentation of the learning community over time. The result is often "independent messages with a minimal amount of learner-to-learner interaction" (Curran, Kirby, Parsons, \& Lockyer, 2003). Other studies indicate that threaded discussions are more oriented towards sharing of personal opinions and contain more social and regulative comments than environments that are designed for intentional and collaborative knowledge construction (Hewitt, 1997; Van der Pol, Admiraal, \& Simons, 2006).

In Knowledge Forum any participant, creating a linked network of cross-referenced notes, can enter references to any note. This feature was used in the UTCSP-IFEO program. Figure 2 shows a note containing hyperlinks to a number of other notes, thus enabling a more complex and coherent structuring of the discourse than is enabled by threaded discourse.

Beyond Learning Management Systems: Designing for Interprofessional Knowledge Building in the Health Sciences 


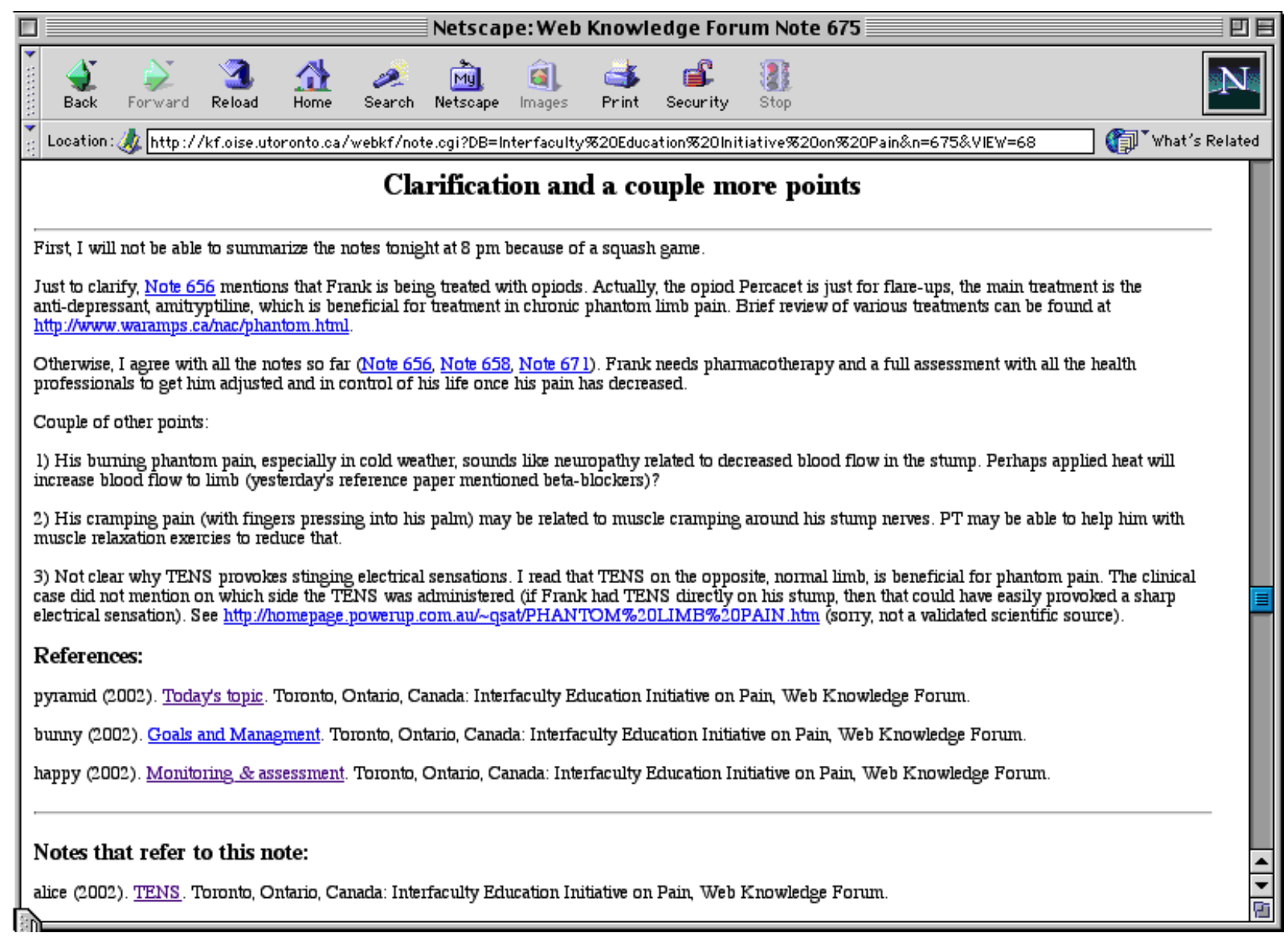

Figure 2: Knowledge Forum 2.0 linking and within note multi-referencing to support convergence of ideas. 
However, cross-referencing alone is not enough to sustain coherent Knowledge Building discourse. The following are three cross-referenced notes produced in Knowledge Forum.

\section{Drug Concerns...more info needed}

...I noticed while reading the letter that one of the reasons Mr. Morris' pain is not under control is that he is actually hesitant to take the acet. $w /$ codeine. One of the first things that I'd do would be to try and figure out what is underlying this hesitancy.

We need to determine:

1. Is it his concern about the side effects of the medication? (i.e., nausea/constipation) If this is so, does he realize that the side effects are treatable?

2. Is it for a social reason? Is it due to pride or a family tradition of avoiding medication unless it is urgently necessary? (I say this because I know my family is like this.)

3. Is he concerned about becoming dependant on the medication?

4. Does he think that the pain is unavoidable? Would he rather deal with the pain than be incapacitated by its treatment?

Once we have dealt with the underlying cause of his hesitancy, we can then address the choice of therapy itself. It is clear that $30 \mathrm{mg}$ of codeine q4-6 is notappropriately reducing his pain.

It is necessary to determine whether or not the pain is nociceptive or neurogenic in nature. Then, according to what is found a new agent can be chosen, likely a more potent analgesic. However, that choice has to be made with the input of the patient, taking into account the answers to the questions above.

Comments anyone?

Author: island

Creation Date: Mar 182002 (19:00:37)

Beyond Learning Management Systems: Designing for Interprofessional Knowledge Building in the Health Sciences 


\section{Other treatment options}

...We have been talking a lot about the pharmacological treatment of pain. Usually medication is first line. There are however other options. For example

TENS - transcutaneous electrical nerve stimulation, or local nerve blocks. Also we should keep in mind a role for complementary and alternative medicine.

Acupuncture fits very nicely with the gate theory of pain.

Author: sonic

Creation Date: Mar 182002 (21:23:22)

\section{Treatment possibilities}

... the first step is to have an interdisciplinary team assessment or some type of comprehensive assessment that shows us his current status then ask him what his goals are once we know his goals, compliance with treatment is that much easier Frank's family will ideally become a foundation of support and understanding.

Author: sparkle

Creation Date: Mar 182002 (21:51:13)

As can be seen, these notes provide first steps toward formulating a collaborative approach to treating the patient whose case is being examined. However, further progress would require further consideration of the treatment possibilities and probably additional students joining the dialogue. Present affordances of Knowledge Forum and ones under development can help this happen. For one thing, the initial set of three notes needs to be viewable as a cluster. Students never saw the notes clustered as shown above, but visualization tools available in the current version of Knowledge Forum will identify clusters based on note linkages, thus enabling a new view to be created that will be focused on the linked ideas. We discuss visualization tools in a later section, but first we discuss facilities that can greatly enrich possibilities for visualizations and, in turn, higher levels of discourse.

Multifaceted "idea tagging" helps an author identify the essence of a note and reflect on it more deeply. In turn, tags provide a more comprehensive system of note links to extend possibilities for new view creation and higher-level knowledge work. As a simple example, a keyword "wand" allows a user to highlight a word in a note. Keywords then serve as search parameters so notes sharing designated keywords can be viewed as a cluster. Similarly larger segments of text can be highlighted as "big" or "promising" ideas (labels are customizable) and Beyond Learning Management Systems: Designing for Interprofessional Knowledge Building in the Health Sciences 
searches allow these ideas to be retrieved for further development, with ideas prioritized based on number of "hits". Because the scaffolds are customizable they can support whatever form of discourse the community is particularly interested in--diagnoses, causes, theories, analogies, and so forth. As Chuy et al., (present issue) demonstrate, scaffolds can raise the level of discourse beyond normal developmental expectations. And since scaffolds can facilitate afterthe-fact analysis of ideas, as well as provide support for the generation of new ideas, they can be designed to support analysis of student notes by students. For example, after the first day of work students might use the following scaffolds to analyze their progress: "An idea that represents our point of greatest progress," "A misconception impeding progress...", "We haven't followed through with...." Note the emphasis on how "we" are doing, with shift to community knowledge, collective responsibility rather than individual note evaluations.

Multifaceted marking of ideas within notes provides a layer of intentional, reflective work, to help the community go beyond idea diversity and information overload to rise above to a more focused and coherent set of ideas to drive work forward. "Idea tagging" also enriches the type and quality of visualizations, helping the community shift from knowledge sharing to Knowledge Building.

Information visualization is a powerful tool for searching, filtering, and transforming large amounts of data into a form that facilitates human interaction with it. Knowledge Forum visualization tools help users explore and understand note and view contents using the idea tags mentioned above and information stored for notes and views (creator, date of creation, revision, and so forth). As elaborated below, visualizations include social network (also see Philip, present issue) and semantic analyses. Figure 3, for example, is a reconstruction of all the notes in a large Knowledge Forum database, reconstructed in about 30 seconds, to show semantic near-neighbour notes at the centre with more distant neighbours at the periphery. A number of visualizations are also presented in Hong et al. (present issue).

Beyond Learning Management Systems: Designing for Interprofessional Knowledge Building in the Health Sciences 


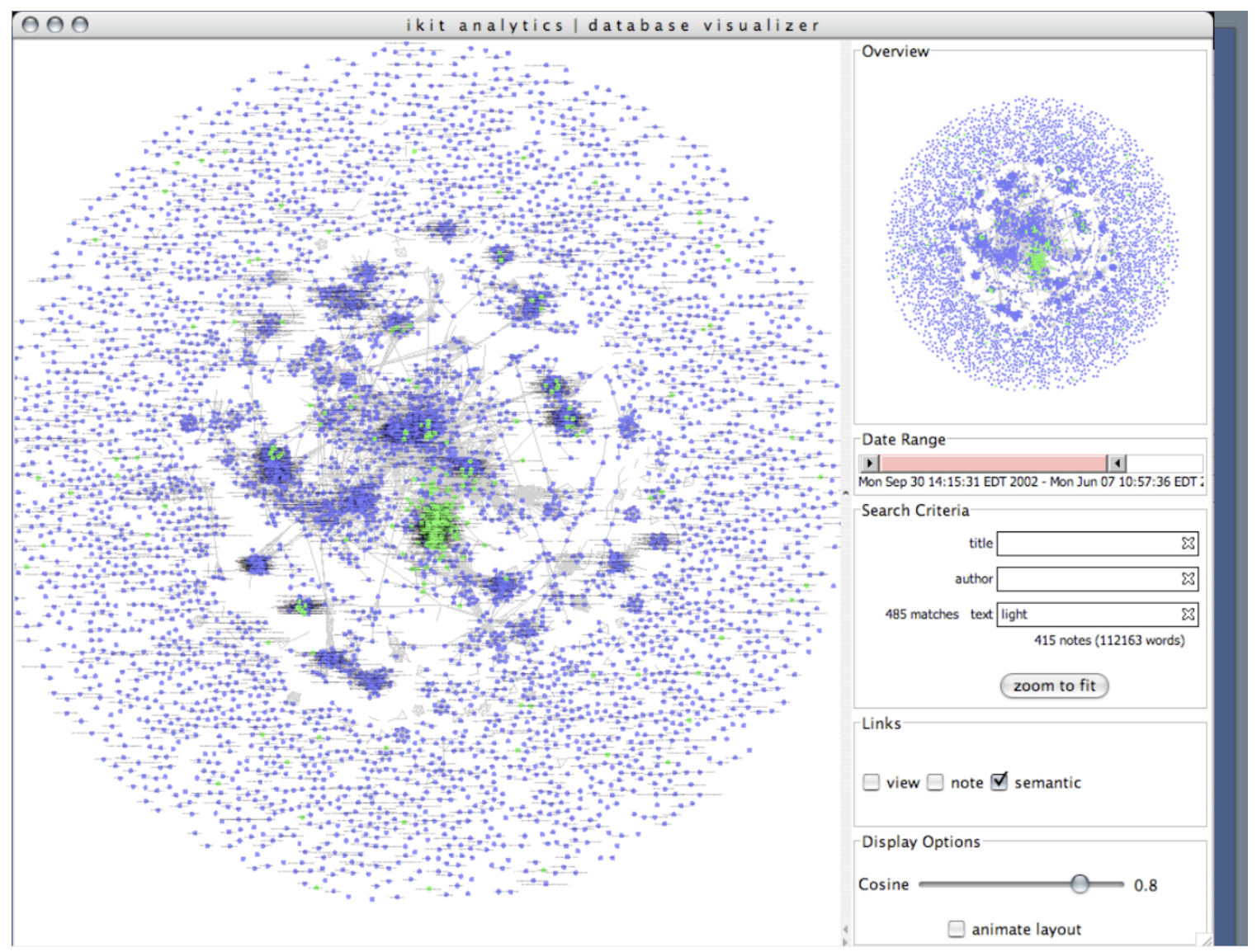

Figure 3: Visualization with semantic near-neighbour notes at the centre and more distant neighbours at the periphery (Visualizer Tool, Teplovs \& Scardamalia, 2007)

The design challenge in using these visualizations for Knowledge Building is to support real-time interaction and modification of information represented in the visualization. In our experience the form of visualization users have found most helpful is one that filters out all notes other than those that meet a small number of criteria so that the visualization dramatically lowers the amount of information to be processed. For example, users might wish to bring all notes with the scaffold support "A misconception impeding progress...," forward, so what they see and work with on the screen is the small subset of notes tagged with that particular scaffold support.

In summary, important advances in moving discourse to high levels include (a) supports for capturing the key ideas in notes and flexibly characterizing them; (b) scaffolds to raise the discourse to increasingly high levels, and (c) visualizations to focus attention on a subset of notes with a specific goal for advancing collective work. Through such means, and as elaborated below, we should be able to show that students can take over levels of work normally reserved for the teacher and not supported by conventional learning management systems.

Beyond Learning Management Systems: Designing for Interprofessional Knowledge Building in the Health Sciences 


\section{Integration of sociocognitive functions as distinct from an assortment of separate tools}

In the WebCT 2.0 learning management system, separate areas are used for different functions such as discussion, readings, access to multimedia resources, and so forth. Although WebCT, Inc. has since merged with Blackboard Inc. and new features have been added, the concept of separateness seems to be an enduring characteristic of learning management systems. Thus, as shown in Figure 4, the first thing that Pain Week students had to do on logging in to WebCT 2.0 was select a place to go.

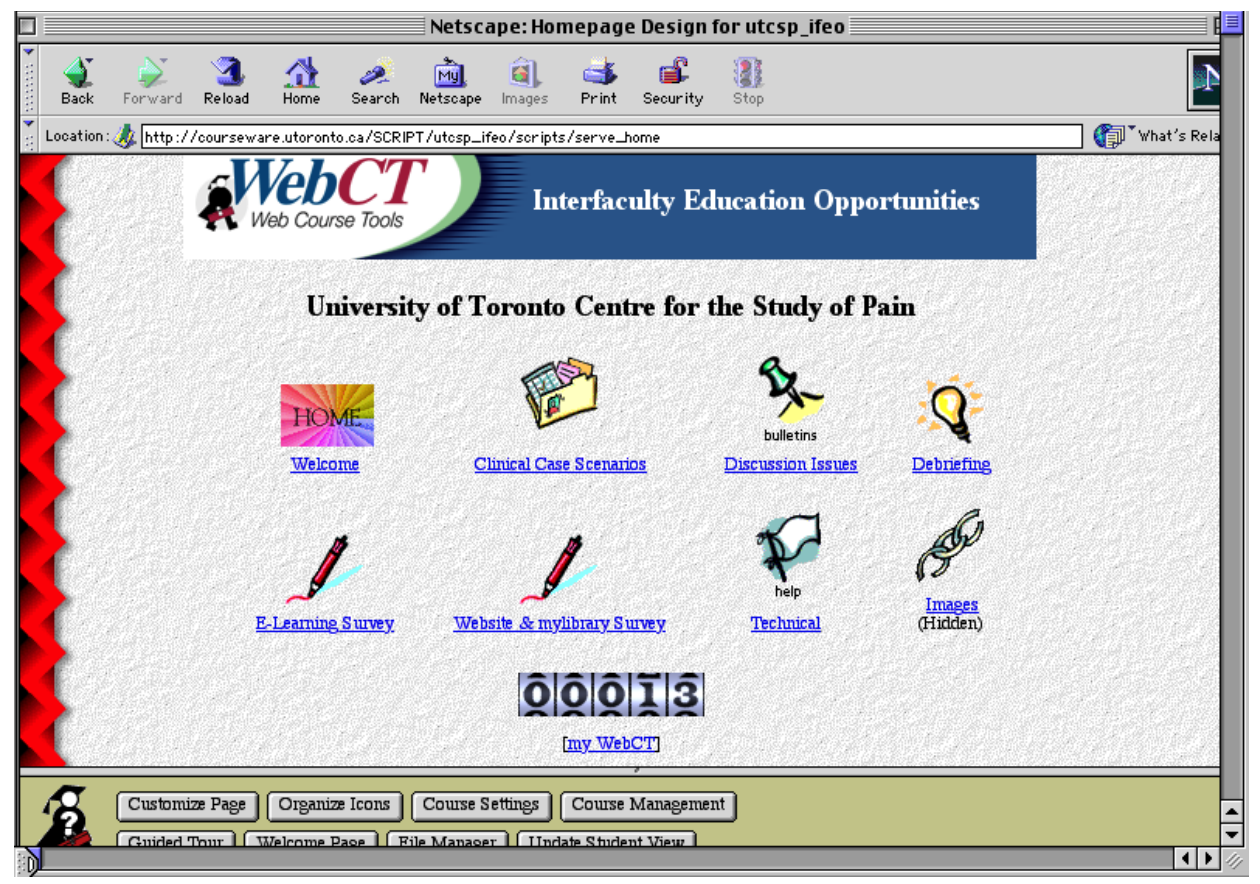

Figure 4: WebCT 2.0 homepage with separate areas for multimedia, text-based discussion, and images.

In contrast to executing different functions in different spaces, the Knowledge Building dynamic is to prevent ideas from being encapsulated in notes, inquiry threads, separate spaces, or particular representational media. To support knowledge creation it is essential to support emergence and opportunism rather than work in contexts where the problems and means of approaching them are predetermined and closed. In line with this challenge, and to support sustained knowledge work, it is important to (a) ensure real ideas, authentic problems reflect the core work of the organization, the ideas of its creators, and their capacity as designers to establish meeting spaces for people and ideas; (b) ensure that community knowledge advancement becomes the norm, by creating emergent hyperlinked media-rich communitydesigned spaces that represent collective, not just individual knowledge and accomplishment; (c) support recursion in all functions so that rise above notes and views support unlimited embedding of ideas with a higher, more integrative level of work always possible; (d) ensure every object can be an object of discourse, fostering pervasive Knowledge Building and constructive uses of authoritative sources; and (e) provide seamless integration with WWW

Beyond Learning Management Systems: Designing for Interprofessional Knowledge Building in the Health Sciences 
resource and presentation possibilities. Knowledge Forum development aims to achieve these goals.

As one small indication of work in this direction, Knowledge Forum incorporates graphics tools. As the "Sedation" note illustrated in Figure 5 suggests, images can be incorporated with text (also see Gan, et al., present issue). Embedded graphics tools make it possible to modify, mark up, and critique images in a note, as well as create backgrounds for views so they provide more effective contexts for ideas. The multimedia notes and design spaces contrast with learning management systems that use text-only discussion notes with images outside the discussion board, accessible via URLs in the discussion note. It also contrasts with the typical note list on a blank background, with users having no capacity to control the placement of ideas or context for them. The importance of visual representation has been well documented, and is particularly important in the health sciences (Arnheim, 1969; Mayer, 2005; Tufte, 2006). The Gan et al. paper (present issue) provides further indication of the importance of multimedia notes and views at all educational levels.

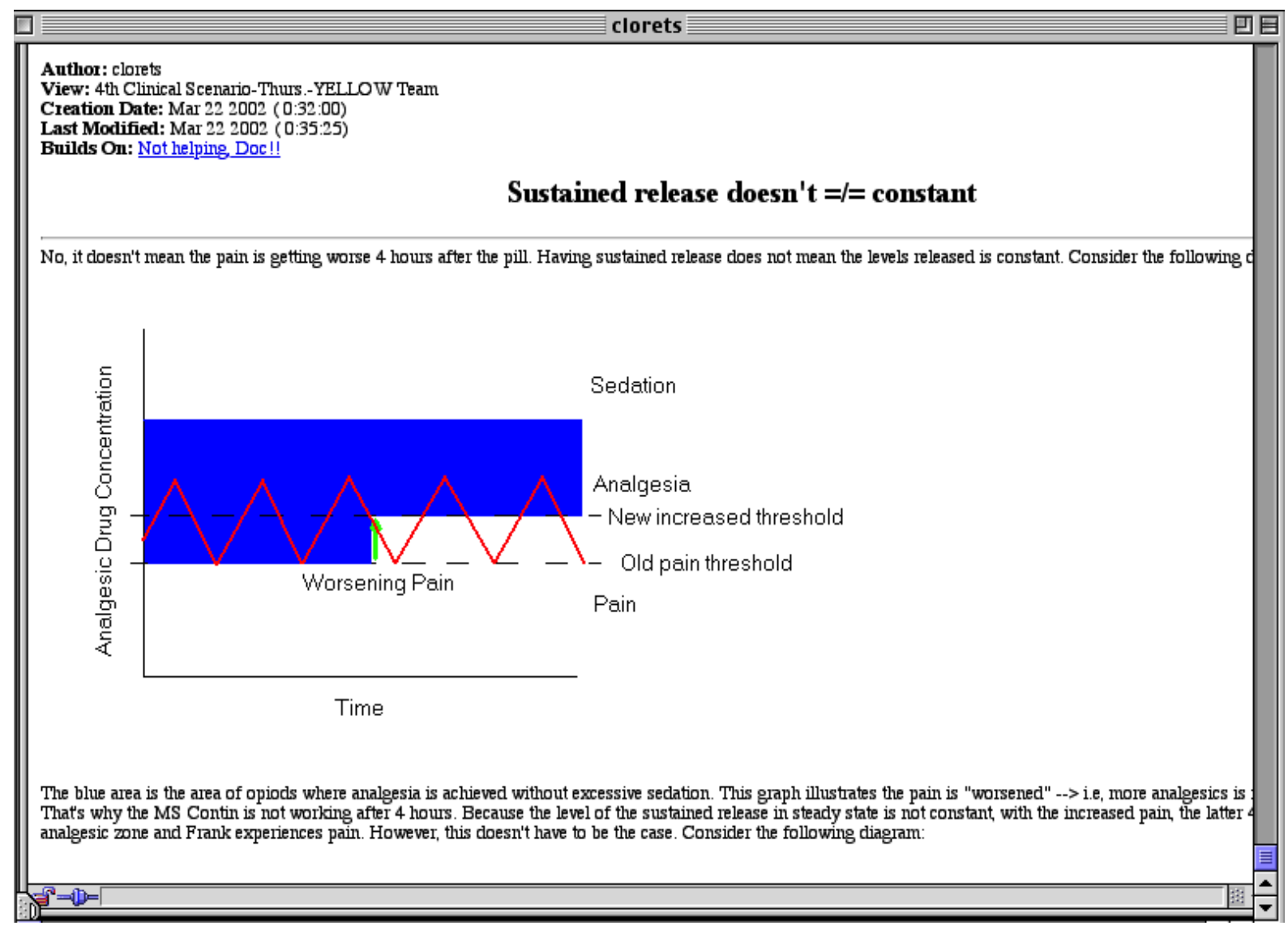

Figure 5: Knowledge Forum 2.0 multimedia communal knowledge space enables recursive work with ideas expressed in text and graphics.

Beyond Learning Management Systems: Designing for Interprofessional Knowledge Building in the Health Sciences 
Members of the committee developed a clinical case on phantom-limb pain to support interprofessional problem solving. Video vignettes were filmed using standardized patients, and integrated with real patient videos to engage students with "the patient" and vividly with the issues (Figure 6).

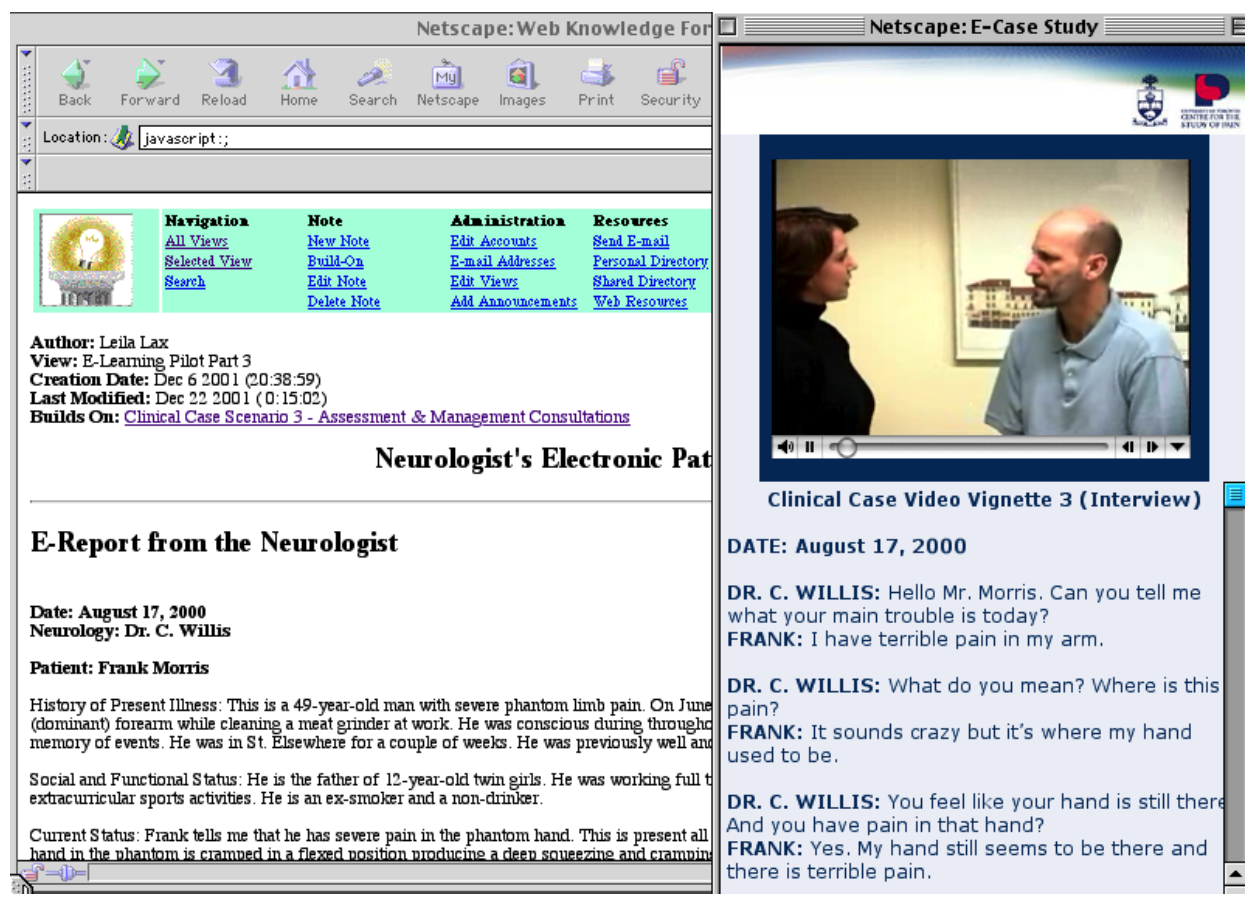

Figure 6: Authentic multimedia clinical case scenarios unfolded daily in Knowledge Forum 2.0.

To support discussion of the clinical-case, scenarios that framed the discussions each day were presented in five different discussion boards or views: Day 1 focused on neurophysiology, Day 2 on pain assessment, Days 3 and 4 on patient management, and Day 5 on ethical issues and workers' compensation. For each clinical scenario discussion, issues were presented to the students with an overview of pre-defined pain curriculum learning objectives. Groups were structured so that interdisciplinary teams were engaged in all discussions. Experts facilitated the online work.

The strength of the clinical case, multimedia presentation format, and engagement of interdisciplinary teams was evident in students' strong, positive responses, and high levels of engagement. Nonetheless, Knowledge Building potential may well have been lost as discussion in WebCT 2.0 and in Knowledge Forum 2.0 took place in separate, predefined course spaces, with the video only accessible via a URL. The design challenge in integrating graphics, video, and other media is not simply that of integrating graphics and text but of breaking down barriers to idea improvement which can be facilitated through tighter linkage between knowledge spaces (see Hong et al., present issue).

Knowledge Forum's Analytic Toolkit can be used, as suggested in Figure 3, to visualize the database in new ways. The user simply needs to identify the parameter for the search of text,

Beyond Learning Management Systems: Designing for Interprofessional Knowledge Building in the Health Sciences 
tags, groups, and time frame. Notes can then be aligned on the basis of relationships not visible in the discussion board or view. If the interest is in neurophysiology, presuming ideas of importance may exist outside the Day 1 view focused on that topic, priority words in neurophysiology can be entered into the search criteria and a new visualization of the database will show near-neighbour notes at the centre with more distant neighbours at the periphery. Such searches can easily be extended to notes and resources in the course library or the Internet at large. The richer the network of links between notes and views, the more points of potential convergence. Through such sustained and varied engagement, ideas acquire new properties, in contrast to learning management systems for which much of the structure, organization, and assignment is predetermined.

Integrated sociocognitive functioning is supported by another design goal for Knowledge Forum: any web accessible object should be treatable as an object of Knowledge Building discourse. Thus students can mark up, annotate, build on, add idea tags to text, graphics, video-any object. New open source tools make such functions increasingly possible, while new open and free learning environments (videos, simulations, games, and so forth --see, for example, http://oli.web.cmu.edu/openlearning//) make them increasingly important. Accordingly, rather than having the phantom pain case video as a watch-only resource with students discussing it in a separate space, students could interact with it as they view it and have access to annotations, references, and so forth, added by others. Furthermore, the links could traverse contexts and communities, not necessarily be limited to class or course participants, and students could contribute to and build on these other resources. New facilities of this sort are under development by several teams. In our own designs we are taking care to ensure that the video, simulation, etc., operates in a natural way, supporting the discourse surrounding it while in no way interfering with viewing it or using it as intended in its original design.

Treating course readings as objects of inquiry opens additional avenues for tighter integration of sociocognitive functions. In knowledge creating organizations the goal of reading is not simply to discuss the reading, but more typically, to find important new information so as to advance the organization's work, to generate more design ideas, to identify and solve problems at the cutting edge of the field, to monitor that cutting edge and increase the chances of moving it forward. Relevant readings are not pre-set, but grow as new problems emerge and new efforts to find relevant resources pull in more information from varied sources. These readings likewise need to be linked, annotated, incorporated into the active working space, and in other ways treated as object of inquiry rather than read-only authoritative sources. The goal is to help students make more constructive use of authoritative sources.

Coursework typically represents a world of work separate from the broader work of the discipline or organization. We have tried to show that this need not be the case, that if education is carried on in a Knowledge Building environment it can connect seamlessly and at a deep level with the productive work of an organization or profession and engage students in a progressive enterprise in which they are contributing to shared intellectual work.

Beyond Learning Management Systems: Designing for Interprofessional Knowledge Building in the Health Sciences 


\section{Resources for multidimensional social and cognitive assessment that go beyond common participation indicators and instructor-designed quizzes and analyses}

Most, if not all, learning management systems provide basic tools for monitoring participation, administering and scoring quizzes, and managing grading. As suggested at one learning outcomes management site (http://www.blackboard.com/Solutions-by-Market/HigherEducation/Blackboard-Learn-for-Higher-Ed/Capabilities/Outcomes-Assessment.aspx), it is possible to not only grade tests, but also provide feedback so students can learn from the questions they miss. Learning Outcomes Systems will often also claim to help assess teaching and learning practices as well as an entire cycle of assessment, using portfolios, artifacts and rubrics.

Knowledge Forum's Analytic Toolkit similarly provides a broad array of tracking tools and its set of assessment applets is growing. It does not, at this time, support course management, but could be linked to open source facilities that do. What is distinctive to assessment as supported by Knowledge Forum is tools to foster continual advancement and emergence of new competencies rather than simply assess what has been done. In a paper titled "New Assessments and Environments for Knowledge Building," Scardamalia et al., (in press) argue that education to address $21^{\text {st }}$ century needs requires not only targeting recognized objectives, but enabling new objectives-particularly new objectives that emerge from authentic knowledge creation. Knowledge Building environments are required to accomplish this because, as in mature knowledge-creating organizations, the core work is the production of new knowledge, artifacts, and ideas of value to the community. New environments can bring out things students are able to do that are obscured by current learning environments and assessments.

We consider procedures and findings from the interfaculty pain education initiative as a segue to discussion of new assessment possibilities. Of great importance to the course on pain management was the identification of misconceptions - mistaken beliefs or notions - that entered the online forum. How frequently did students enter notes containing misconceptions? Did the misconception spread? What should the expert's role be in ensuring misconceptions are identified and corrected? These issues were of great concern and in an effort to address the problem a detailed coding scheme was used to determine the extent to which student notes contained misconceptions. It was developed by Lax, Watt-Watson and Pennefather, based on previous work by Burtis, Chan, Hewitt, Scardamalia, and Bereiter (1993). Extensive analysis was conducted of the notes of one interdisciplinary team working in Knowledge Forum. This team, known as the Green team, was selected because each member of the interdisciplinary team had sustained contributions over the 5 -days, and this seemed an interesting context for determining the extent to which misconceptions existed, and whether they flourished or were corrected. Each note was scored by a pain expert according to the scheme set out in the following inventory of misconceptions found in the database (Table 1).

Beyond Learning Management Systems: Designing for Interprofessional Knowledge Building in the Health Sciences 
Table 1: Results of Pain Conceptions/Misconceptions Analysis

\begin{tabular}{|c|c|}
\hline \multicolumn{2}{|l|}{ A. Frequency of: } \\
\hline 1. Relevant knowledge/concept(s) in comment(s) & 43 \\
\hline 2a. Misleading knowledge/concept(s) in comment(s) & 15 \\
\hline $\begin{array}{l}\text { 2b. Knowledge gap(s) formulated into a problem of } \\
\text { inquiry }\end{array}$ & 1 \\
\hline \multicolumn{2}{|l|}{ B. Enquiry about Misconceptions \&/or Knowledge Gaps } \\
\hline $\begin{array}{l}\text { 3. No awareness of misconception stated in } \\
\text { comment(s) }\end{array}$ & 7 \\
\hline $\begin{array}{l}\text { 4. Awareness of misconception stated in } \\
\text { comment(s) }\end{array}$ & 1 \\
\hline $\begin{array}{l}\text { 5. Awareness of knowledge gap stated in } \\
\text { comment(s) }\end{array}$ & 1 \\
\hline \multicolumn{2}{|l|}{$\begin{array}{l}\text { C. Responses to Misconceptions } \\
\text { The misconception was: }\end{array}$} \\
\hline 6. Reinforced by other contributors & 1 \\
\hline 7. Not addressed further & 1 \\
\hline 8. Partially resolved & $\begin{array}{c}3 \text { (by others) } \\
1 \text { (by self) } \\
0 \text { (by facilitator) }\end{array}$ \\
\hline 9. Resolved & 0 \\
\hline \multicolumn{2}{|l|}{$\begin{array}{l}\text { D. Responses to Relevant Concepts } \\
\text { The concept was: }\end{array}$} \\
\hline 10. Reinforced by other contributors & 9 \\
\hline 11. Not addressed further & 4 \\
\hline 12. Partially reinforced, queried or expanded & $\begin{array}{c}20 \\
\text { (15 by others) }\end{array}$ \\
\hline 13. Misinterpreted & 1 \\
\hline
\end{tabular}

Beyond Learning Management Systems: Designing for Interprofessional Knowledge Building in the Health Sciences 
An example of a note judged to include a misconception is presented below.

\section{Treatment options}

We all seem to agree there are a few causes for his pain:

1) Tissue injury - acute, caused by the amputation or after and would best be managed via potent analgesics. (A.1-F, D.10)

2) Neuropathic pain - more of a chronic pain which requires more modalities to treat e.g., tricyclics. (A.1-F, D.10)

3) Psychological undertones - best treated non-pharmacologically to ensure that pt. continues to function and has a positive outlook and is able to cope with everyday life. (A.1-F, D.10)

*It is imperative to determine the cause of his pain! (A.2-F, D.10) Granted his pain will be treated but we must know the precise cause of the pain if we are to treat it effectively. The prescription for Tyl 3's would have addresses (1) (A.2, B.3, C.7) but unlikely to have addressed (2) or (3). (A.1-F, D.11)

Author: iceman

Creation Date: Mar 182002 (18:39:26)

*The expert's explanation of the misconception was this: "cause vs. type-can't always determine cause, which is a problem for people with chronic pain." Using a search including the word "cause" and the name of the author we find that the same author wrote the following note shortly after writing the text above.

\section{Geronimo!!}

... We can deal with the physiological side affects by offering other drugs. It is more prudent to find out any psychological or behavioural problems as outlined above.

We all agree then that the cause of the pain is the most important part of treating it. We can't treat pain if we know not whence it comes from!

Author: iceman

Creation Date: Mar 182002 (19:08:14)

Beyond Learning Management Systems: Designing for Interprofessional Knowledge Building in the Health Sciences 
This second note, however, was not evaluated in relationship to the first, as each note was reviewed independently. We provide this additional information as the start of our discussion of uses and advantages of more comprehensive and automated analytic tools in identifying and scoring misconceptions. Coding of notes indicated that concepts relevant to the course appeared in notes approximately three times as often as misleading concepts. However, a large number of misconceptions were apparent within the Day 1 notes. Some of these misconceptions were only partially resolved in discussions with other students. The conclusion was that explicit feedback from facilitators is needed to deal with misconceptions-a process that is, of course, labour intensive and expensive. It was also noted that a great advantage of the online work is that it brings misconceptions to the foreground.

In line with the concept of emergence and the knowledge creation imperative to continually go beyond current best practice, we consider new forms of data made possible by Knowledge Building environments and why the conclusion that explicit feedback is the only way to address the misconceptions challenge underestimates the potential of Knowledge Building environments. To make this argument we introduce the Knowledge Building principle of concurrent, embedded, and transformative assessment. Concurrent assessment means that the assessment is available instantaneously. Embedded means that it is integral to the workings of the organization rather than being functionally distinct. Transformative means that the evaluation is not simply an account of past performance and next immediate steps, but also provides indication of ways individuals and teams can tackle broader problems and situate their work in relation to that of other team members, including teams outside the school walls.

When student discourse is central to the operation of the community, with members contributing to shared, public knowledge spaces, and building on each other's ideas, vast new possibilities for assessment become possible. The possibilities for data generated automatically from student discourse and artifacts seem to have no bounds and allow a community to engage in its own internal assessment, which is both more fine-tuned and rigorous than external assessment. This then serves to ensure that the community's work will exceed the expectations set by external assessors.

In the following section we indicate two forms of analysis enabled by Knowledge Building environments that could allow us to tackle the misconceptions problem in ways that might lead to more substantial educational gains than would follow from direct expert intervention alone.

Specially designed scaffolds can be co-developed with students to engage them more directly in identifying misconceptions. The following scaffolds might help: "An example of cause versus type ..."; A possible misconception ..."; "This is better explained as ..." Could students find the same misconceptions the expert found-or at least a subset? And if so, visualization tools could then bring these misconceptions to the forefront of the view. Further near-neighbour searches could then find linked notes, creating a new misconceptions problem space that would represent an important object of discussion. Additionally, simple keyword searches would bring together related notes, and these could be displayed in chronological order, making it easier to assess change over time. Accordingly it would be evident that the author who wrote the note

Beyond Learning Management Systems: Designing for Interprofessional Knowledge Building in the Health Sciences 
with a misconception actually followed up with a note that went deeper into causes. More targeted viewing of ideas could support more comprehensive assessment. The possibility of automated detection of misconceptions remains to be investigated, although the basic tools are available and can be implemented through Knowledge Forum. The key tool is semantic analysis that measures the conceptual overlap between documents as opposed to simply measuring vocabulary overlap (Landauer \& Dumais, 1997). Given that within a domain the same misconceptions tend to appear repeatedly, it should be possible to assemble a document made up of common expressions of prevailing misconceptions (such as the type = cause misconception). A contrasting document could be selected that covers the same material in an authoritatively approved way. Then for any piece of student writing - such as a set of Knowledge Forum notes or an answer to an essay test question-the semantic distance between the student piece and each of the reference documents could be calculated. Being closer to the misconceptions document than to the authoritative document would serve as a signal that a misconception was likely present, and finer analysis might be able to pinpoint the misconception by identifying words related to it. Although implementation of this work awaits funding, it suggests the exciting possibilities inherent in education organized around student engagement in creating theories, explanations, prescriptions, plans, and other knowledge objects.

\section{Discussion}

Two different technologies were used by educational designers at the University of Toronto to support an interprofessional curriculum in health sciences, dealing with the multiple aspects of pain. The goal of this initiative was to advance current pain knowledge and to engage participants in interprofessional communication. The 5-day course represented an important first step in advancing collaborative Knowledge Building for interprofessional education across a large university campus. Designs for case-based reasoning that were successfully incorporated into two different technological environments included authentic clinical scenarios, clinicianexpert feedback, attention to misconceptions, and interdisciplinary teams functioning interactively and successfully to improve knowledge and understanding about collaborative pain treatment for better patient outcomes.

As part of the commitment on the part of the Faculty of Medicine at the University of Toronto to explore new e-learning environments and to understand the extent to which different technologies can be used to achieve similar goals, WebCT 2.0, a learning management system and Knowledge Forum 2.0, a Knowledge Building environment were compared. In the first design initiative the different technologies were channeled into parallel uses, and it was accordingly possible to demonstrate that both provide effective environments for e-learning. But the primary goal of Knowledge Forum, as a Knowledge Building environment, is to enable education to operate as a knowledge creating process and, in turn, bring the different worlds of knowledge work and e-learning together into one coherent framework. With this challenge in mind, we focused on three technology affordances that, if fully used within a Knowledge Building framework, might produce a different order of results.

Beyond Learning Management Systems: Designing for Interprofessional Knowledge Building in the Health Sciences 
Central to education's becoming a knowledge-creating process is better integration of "belief mode" - the mode of argumentation, persuasion, and critical analysis - and "design mode" the mode of theorizing, invention, and idea improvement. Currently, work in design mode is seriously underrepresented in most coursework. As suggested in Figure 7, better integration and representation of work in design mode requires systemic change along a number of dimensions. The present paper has dealt with the potential of a Knowledge Building technology to support such change. Three important contributions that a Knowledge Building technology can make over and above those of courseware are (a) support of sustained Knowledge Building discourse that involves multiple idea linkages and movement of discourse toward higher-level organizations of ideas, (b) integration of various sociocognitive functions so that they have combined strength rather than representing different activity spaces, and (c) possibilities for continual formative assessment driven by Knowledge Building goals.

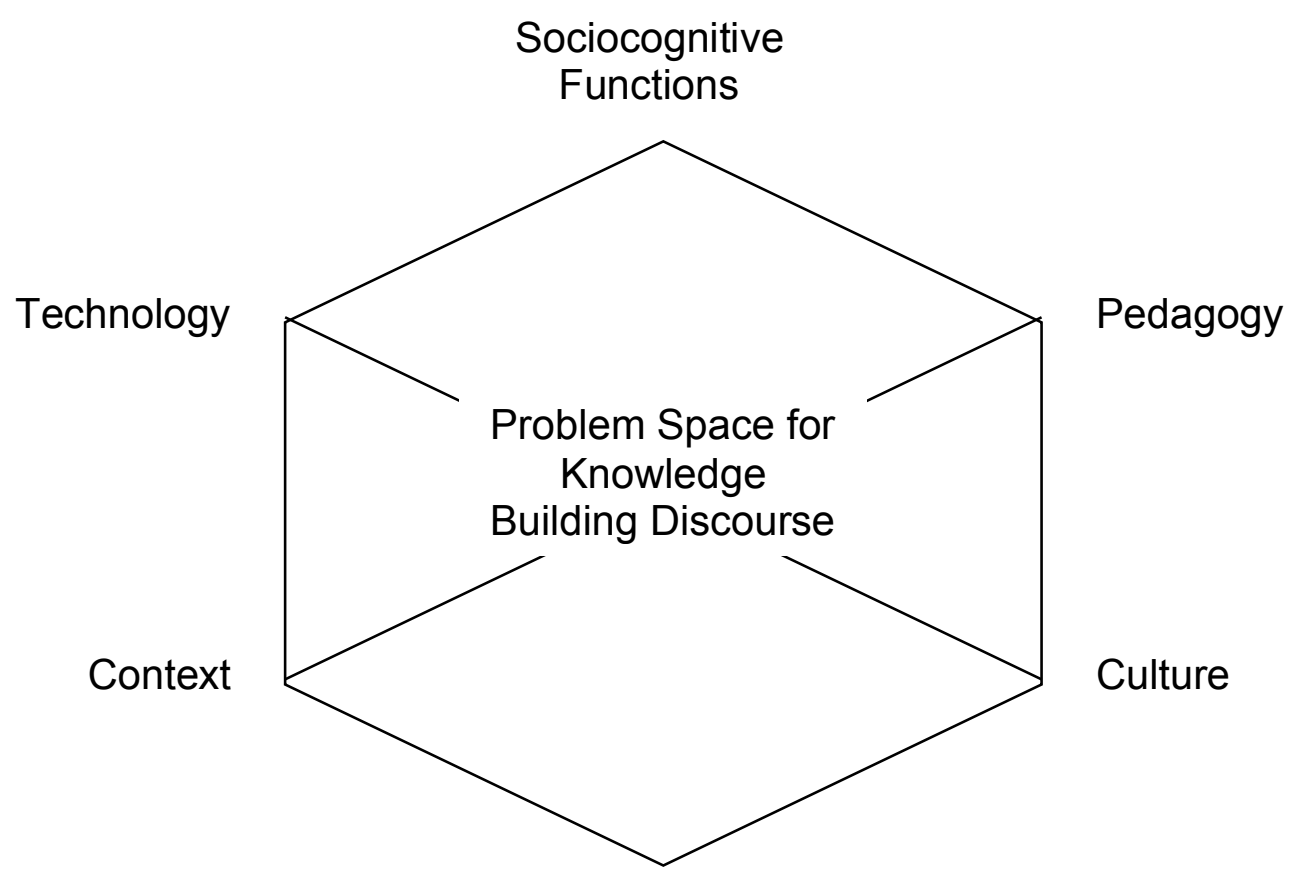

Community

Figure 7: Knowledge Building framework for systemic change.

\section{Acknowledgements}

We gratefully acknowledge education research funding for this study from the Council of Health Science and Social Work Deans, Dean Catharine Whiteside (Chair), University of Toronto Academic Priorities Fund; and the University of Toronto Centre for the Study of Pain, Dr. Mike Salter (Director). We are also grateful for research support provided by the SSHRC, Initiatives in a New Economy - Beyond Best Practice: Research-based Innovation in Learning and Knowledge Work, Institute for Knowledge Innovation and Technology.

Beyond Learning Management Systems: Designing for Interprofessional Knowledge Building in the Health Sciences 


\section{References}

Arnheim, R. 1969. Visual thinking. Berkeley, CA: University of California Press.

Barr, H., Koppel, I., Reeves, S., Hammick, M., \& Freeth, D. (2005). Effective interprofessional education: argument, assumption and evidence. Oxford, UK: Blackwell Publishing.

Burtis, J., Chan, C., Hewitt, J., Scardamalia, M., \& Bereiter, C. (1993). Misconceptions in a student-guided research project. Retrieved March 30, 2002 from http://Knowledge Forum.oise.utoronto.ca/abstracts/misconceptions

Chuy, M., Scardamalia, M., Bereiter, C., Prinsen, F., Resendes, M., Messina, R., Hunsburger, W., \& Teplovs, C. (2010). Understanding the nature of science and scientific progress: A theorybuilding approach. Canadian Journal of Learning and Technology, 36(1).

Cooney, M., \& Bielaczyc, K. (2003). Beyond the database: Considering the learning environment writ large. Poster session presented at the IKIT Summer Institute 2003, Toronto, Canada.

Cooper, H., Carlisle, C., Gibbs, T., \& Watkins, C. (2001). Developing an evidence base for interdisciplinary learning: a systematic review. Journal of Advanced Nursing, 35(2), 228237.

Curran, V., Kirby, F., Parsons, E., \& Lockyer, J. (2003). Discourse analysis of computer-mediated conferencing in World Wide Web-based continuing medical education. Journal of Continuing Education in the Health Professions, (23), 229-238.

D’Amour, D., \& Oandasan, I. (2004). Interprofessional education for patient-centred practice: An evolving framework. In Oandasan, I., D’Amour, D., Zwarenstein, M., Baker, K., Purden, M., Beaulieu, MD., et al., (Eds.) Interdisciplinary Education for Collaborative, Patient-Centred Practice: Research \& Findings Report. Ottawa, Canada: Health Canada.

Davie, L., Abeygunawardena, H., Davidson, K., \& Nolan, J. (1998). Universities, communities, and site buildings: exploring three online learning systems: Virtual University, WebCSILE \& MOOkti. Retrieved June 5, 2001 from http://noisey.oise.utoronto.ca/projcool/conferences/ECOO98.html

Gan, Y. C., Scardamalia, M., Hong, H. Y., \& Zhang, J. (2010). Making thinking visible: Growth in graphical literacy, Grades 3 to 4. Canadian Journal of Learning and Technology, 36(1).

Goldberg, M. W., Salari, S., \& Swoboda, P. (1996). World Wide Web Course Tool: An environment for building WWW-based courses. Computer Networks and ISDN Systems, 28(7-11), 1219-1231.

Hall, P., \& Weaver, L. (2001). Interdisciplinary education and teamwork: a long and winding road. Medical Education, 35(9), 867-875.

Hewitt, J. (1997). Beyond threaded discourse. WebNet 97, Toronto, November 1997.

Beyond Learning Management Systems: Designing for Interprofessional Knowledge Building in the Health Sciences 
Hong, H. Y., Scardamalia, M., \& Zhang, J. (2010). Knowledge Society Network: Toward a dynamic, sustained network for building knowledge. Canadian Journal of Learning and Technology, 36(1).

Horsburgh, M., Lamdin, R., \& Williamson, E. (2001). Multiprofessional learning: the attitudes of medical, nursing and pharmacy students to shared learning. Medical Education, 35, 876883.

Landauer, T. K., \& Dumais, S. T. (1997). A solution to Plato's problem: The Latent Semantic Analysis theory of the acquisition, induction, and representation of knowledge. Psychological Review, 25, 211-240.

Lax, L., Singh, A., Scaradmalia, M., \& Librach, L. (2006). Self-assessment for Knowledge Building in health care. QWERTY: Journal of Technology and Culture. 1(2):19-37.

Lax, L., Watt-Watson, J., Pennefather, P., Hunter, J., \& Scardamalia, M. (2002). Pain Week IT \& eLearning components: Project to examine the cost/effectiveness of e-Learning for interfaculty health professional education. Final report submitted to Interprofessional Education Management Committee, University of Toronto, November 26, 2002. Retrieved September 5, 2010 from http://ikit.org/fulltext/Lax_PainWeek_FinalReport_2002.pdf

Lax, L., Watt-Watson, J., Pennefather, P., Hunter, J., \& Scardamalia, M. (2003). Pain Week Knowledge Translation Program: Developing a model of interprofessional Knowledge Building. Paper presented at the Institute for Knowledge Innovation and Technology Summer Institute 2003. Retrieved October 9, 2010 from http://ikit.org/Summerlnstitute2003/posters/lax2.html

Lee, E. Y. C., Chan, C. K. K., \& van Aalst. J. (2006). Students assessing their own collaborative Knowledge Building. International Journal of Computer-Supported Collaborative Learning, 1, 277-307. (SSCI)

Mayer, R. E. (2005). Cognitive theory of multimedia learning. The Cambridge Handbook of Multimedia Learning (pp. 31-48). NY, USA: Cambridge, University Press.

Moss, J., \& Beatty, R. (2010). Knowledge Building and mathematics: Shifting the responsibility for knowledge advancement and engagement. Canadian Journal of Learning and Technology, 36(1).

Philip, D. N. (2010). Social network analysis to examine interaction patterns in knowledgebuilding communities. Canadian Journal of Learning and Technology, 36(1).

Scardamalia, M. (2003). Knowledge Building environments: Extending the limits of the possible in education and knowledge work. In A. DiStefano, K. E. Rudestam, \& R. Silverman (Eds.), Encyclopedia of distributed learning (pp. 269-272). Thousand Oaks, CA: Sage Publications.

Beyond Learning Management Systems: Designing for Interprofessional Knowledge Building in the Health Sciences 
Scardamalia, M., \& Bereiter, C. (2003). Knowledge Building. In Encyclopedia of Education, Second Edition. New York: Macmillian Reference.

Scardamalia, M., \& Bereiter, C. (2006). Knowledge Building: Theory, pedagogy, and technology. In K. Sawyer (Ed.), Cambridge Handbook of the Learning Sciences (pp. 97-118). New York: Cambridge University Press.

Scardamalia, M., Bransford, J., Kozma, R., \& Quellmalz, E. (in press). New assessments and environments for Knowledge Building. Assessment and Learning of 21st Century Skills.

Sun, Y., Zhang, J., \& Scardamalia, M. (2010). Developing deep understanding and literacy while addressing a gender-based literacy gap. Canadian Journal of Learning and Technology, 36(1).

Tufte, E. R. (2006). Visual explanations: Images and quantities, evidence and narrative. Cheshire, $\mathrm{CN}$ : Graphics Press.

Teplovs, C., \& Scardamalia, M. (2007). Visualizations for Knowledge Building assessment. Paper presented at the 11th Annual Knowledge Building Summer Institute, Toronto, Ontario, Canada. http://ikit.org/SummerInstitute2007/Highlights/SI2007_papers/48_Teplovs.pdf

Van der Pol, J., Admiraal, W., \& Simons, P. R. J. (2006). The affordance of anchored discussion for the collaborative processing of academic texts. International Journal of Computer Supported Collaborative Learning, 1(3), 339-357. DOI:10.1007/s11412-006-9657-6.

Watt-Watson, J., Hunter, J. , Pennefather, P., Librach, L., Raman-Wilms, L., Schreiber, M., ... \& Salter, M. (2004). An integrated undergraduate pain curriculum, based on IASP curricula, for six health sciences faculties. Pain, 110(1), 140-148.

Zhang, J., Scardamalia, M., Lamon, M., Messina, R., \& Reeve, R. (2007). Socio-cognitive dynamics of Knowledge Building in the work of nine- and ten-year-olds. Educational Technology Research and Development, 55(2), 117-145.

Zwarenstein, M., Reeves, S., Barr, S., Hammick, M., Koppel, I., \& Atkins, J. (2001). Interprofessional education: effects on professional practice and health care outcomes. Cochrane Library, (1)1-13.

Beyond Learning Management Systems: Designing for Interprofessional Knowledge Building in the Health Sciences 